\title{
A Novel Anatomical Locking Plate Combined with an Anterior Column Screw and Magic Screw for Acetabular Fractures Involving Both Columns: Reduction Effect and Functional Outcomes
}

\section{Gongzi Zhang}

Chinese PLA General Hospital

Shuwei Zhang

Chinese PLA General Hospital

Yi Sui

Chinese PLA General Hospital

\section{Xiang Wang}

Chinese PLA General Hospital

\section{Xiuyun Su}

Chinese PLA General Hospital

\section{Zuo Cao}

Chinese PLA General Hospital

\section{Shijie Luo}

Chinese PLA General Hospital

\section{Peifu Tang}

Chinese PLA General Hospital

\section{Lihai Zhang ( $\square$ zhanglihai74@qq.com )}

Department of Orthopedics, Chinese PLA General Hospital https://orcid.org/0000-0003-3172-6309

Research article

Keywords: acetabular fracture, anatomical locking plate, anterior column screw, Magic screw

Posted Date: October 21st, 2020

DOl: https://doi.org/10.21203/rs.3.rs-94005/v1

License: (1) This work is licensed under a Creative Commons Attribution 4.0 International License. Read Full License 


\section{Abstract}

Background: A novel anatomical locking plate (NALP) was designed. The NALP is fixed via an anterior column screw and a Magic screw to apply pressure on the acetabular fracture ends. This study was performed to compare the reduction effect and clinical outcome of the NALP versus the anatomical locking plate (ALP) for acetabular fractures involving both columns.

Methods: From January 2013 to January 2018, 22 patients with acetabular fractures involving both columns were treated using the NALP or ALP in a single institution. The general condition and type of fracture were recorded. The NALP and ALP groups were compared regarding the Letournel fracture classification, operative approach, time from injury to operation, intraoperative bleeding volume, and operation time. The radiographic reduction outcome and hip function at final follow-up were compared between the two groups based on the Matta scores and Harris hip scores, respectively.

Results: The NALP was used in 10 patients, while the ALP was used in 12. Three patients had transverse fractures, 12 had transverse fractures involving posterior wall, and 7 had double-column fractures. The two groups had no significantly differ regarding sex, age, affected side, Letournel fracture classification, operative approach, or follow-up duration. The time from injury to the operation was $20.70 \pm 1.2$ days in the NALP group and $13.17 \pm 7.5$ days in the ALP group $(p=0.089)$. The operation time was $332.20 \pm 128.9$ minutes in the NALP group and 257.50 \pm 91.6 minutes in the ALP group $(p=0.128)$. The intraoperative blood loss volume was $1550.00 \pm 869.5 \mathrm{ml}$ in the NALP group and $666.67 \pm 370.1 \mathrm{ml}$ in the ALP group $(p=0.011)$. The Matta score at final follow-up was $1.10 \pm 0.8$ in the NALP group and $2.46 \pm 1.9$ in the ALP group $(p=0.045)$. The Harris hip score at final follow-up was $87.50 \pm 10.5$ in the NALP group and $81.00 \pm 10.1$ in the ALP group ( $p=0.0782)$.

Conclusion: The NALP achieves adequate compression of the acetabular fracture ends and obtains stronger fixation than the ALP.

Trial registration: ChiCTR,ChiCTR2000030825. Registered 15 March 2020 - Retrospectively registered, http://www.chictr.org.cn/ChiCTR2000030825

\section{Introduction}

Acetabular fractures generally occur as a result of severe trauma, which makes the fractures more complicated because of the presence of concomitant bone defects $[1,2]$. Therefore, the treatment of acetabular fractures remains challenging. The gold standard treatment for complicated acetabular fractures is open reduction and internal fixation $[3,4]$.

With the aging of the population, increasing numbers of acetabular fractures are being caused by minor trauma. This type of acetabular fracture generally involves poor bone condition and complex fracture types and has greater reduction and fixation requirements [5-7]. For double-column acetabular fractures, such as transverse and T-shaped fractures, fixation via the posterior approach alone cannot achieve 
adequate pressurization of the fracture line anteriorly, resulting in poor fracture reduction[8]. Furthermore, it is often difficult to use a plate to compress the fracture ends, even when two skin incisions are created. As a result, the surgeon must use anterior or posterior column screws to assist in compression, which increases the surgical difficulty $[8,9]$.

Previous research has established the mean surface morphology of the acetabulum of Chinese patients using point cloud data from 171 three-dimensional computed tomography models [10,11]. This information has been used to develop a novel anatomical locking plate (NALP) with screw hole threads that facilitate screw fixation in the appropriate acetabular locations to avoid screw penetration, decrease the incidence of traumatic arthritis, and facilitate early mobilization via strong internal fixation $[10,11]$. The NALP uses anterior column screws and Magic screws to achieve adequate compression of the anterior and posterior columns, respectively [12]. And the NALP with two screws form an inverted Yshaped structure to effectively restore the normal mechanical structure of acetabulum. The designated channel openings and travel paths of the anterior and posterior column screws were based on our early studies of the anterior column screw and the Magic screw [12, 13] (Fig. 1).

The purpose of our present study was to compare the clinical treatment effects (including the fracture reduction, postoperative function status) of the NALP versus a conventional anatomical locking plate (ALP) for acetabular fractures involving both columns.

\section{Patients And Methods}

The present study was approved by the ethics committee of our institution, and written informed consent was obtained from all patients for the publication of individual clinical details and accompanying images. The study cohort comprised 22 patients with double-column acetabular fractures (including transverse and T-shaped fractures) who were treated in our institution from January 2013 to January 2018.

\section{Inclusion and exclusion criteria}

The inclusion criteria were an age of $\geq 18$ years, acetabular fracture involving both columns, and provision of informed consent. The exclusion criteria were unstable vital signs, prior acetabular fractures, severe systemic disease, blood coagulation dysfunction, and unsuitability for the study for other reasons.

\section{Surgical technique}

All operations were performed by the same group of surgeons with the patient under general anesthesia. The Kocher-Langenbeck approach, ilioinguinal approach, or combined anterior and posterior approach were used as appropriate based on the individual conditions in each case. K-wires were used to reduce the fracture fragments. After reduction, fixation was achieved using the NALP or ALP. The NALP was 
securely attached to the back of the acetabulum, and the locking screw was safely located away from the acetabulum. The airfoil structure achieved good coverage of the top of the acetabulum. Two hollow compression screws were inserted into the anterior and posterior columns through two unlocked holes (Fig. 2).

\section{Postoperative protocol}

Isometric contraction training of the lower limbs commenced immediately after anesthetic recovery. Visual analog scale scores were used to assess the pain severity on postoperative day $3[14,15]$. All patients remained non-weight-bearing for 4 weeks postoperatively. Partial weight-bearing with crutches or a walker was then permitted as tolerated. Most patients progressed to full weight-bearing within 3 months postoperatively.

\section{Basic data}

The patients' age, sex, body mass index, and other basic data in each group were recorded. The fractures were classified in accordance with the Letournel classification system.

\section{Operative data}

The total operation time for each patient was calculated based on the procedure start and end times recorded by the anesthesiologist. The surgical approach and intraoperative blood loss volume were recorded.

\section{Radiographic and functional assessments}

Clinical and radiographic examinations were performed by two independent assessors at 1, 3, 6, and 12 months postoperatively. An experienced orthopedic trauma surgeon assessed the reduction outcome on the most recent pelvic radiographs available (anterior-posterior, obturator oblique, and iliac oblique). The surgeon who performed the clinical assessments was blinded to the group assignments. The Harris hip scores and Matta radiographic scores at final follow-up were used to evaluate the clinical efficacy $[4,9$, $16,17]$.

\section{Statistical analysis}

SPSS version 24.0 (SPSS Inc., Chicago, Illinois) was used for statistical analyses. The independent variables were group (NALP and ALP). Continuous variables were expressed as estimated mean \pm SD or median (interquartile range [IQR]). Categorical variables were expressed as counts (\%). The t-test/ANOVA 
and Chi-square/Fisher-exact tests were used for comparisons of continuous and categorical variables, respectively. All testing was 2 -sided, and $p<0.05$ was considered statistically significant.

\section{Results}

\section{Basic and operative data}

Data were collected from 22 patients with acetabular fractures (15 males and 7 females). There were 10 patients in the NALP group and 12 in the ALP group. The two groups were comparable regarding sex, age, affected side, Letournel fracture classification, surgical approach, operative condition, and follow-up duration (Table 1). The mean body mass index in the NALP and ALP groups was $25.72 \pm 7.2 \mathrm{~kg} / \mathrm{m}^{2}$ and $26.63 \pm 6.6 \mathrm{~kg} / \mathrm{m}^{2}$, respectively. In the NALP group, four patients had center hip dislocation and two had posterior dislocation; in the ALP group, four patients had center hip dislocation and three had posterior dislocation. In the NALP group, there were seven cases of acetabular double-column fracture and five cases of transverse acetabular fracture with posterior wall fracture; in the ALP group, there were two cases of acetabular double-column fracture, seven cases of transverse acetabular fracture with posterior wall fracture, and three cases of transverse acetabular fracture. The time from injury to the operation was $20.70 \pm 1.2$ days in the NALP group and $13.17 \pm 7.5$ days in the ALP group. 
Table 1

Patient demographics of the NALP vs ALP

\begin{tabular}{|c|c|c|c|c|}
\hline Category & Subcategory & $\begin{array}{l}\text { NALP }(n= \\
10)\end{array}$ & $\operatorname{ALP}(n=12)$ & $\begin{array}{l}\mathrm{p}- \\
\text { value }\end{array}$ \\
\hline \multirow[t]{2}{*}{ Sex } & Male & 8 & 7 & \multirow[t]{2}{*}{0.381} \\
\hline & Female & 2 & 5 & \\
\hline Age & & $\begin{array}{l}45.50 \pm \\
12.331\end{array}$ & $\begin{array}{l}37.25 \pm \\
17.248\end{array}$ & 0.220 \\
\hline BMI & & $\begin{array}{l}25.72 \pm \\
7.237\end{array}$ & $\begin{array}{l}26.63 \pm \\
6.640\end{array}$ & 0.764 \\
\hline \multirow[t]{2}{*}{ Fracture side } & Left & 7 & 6 & \multirow[t]{2}{*}{0.415} \\
\hline & Right & 3 & 6 & \\
\hline \multirow[t]{3}{*}{ Letournel classification } & Transverse & 0 & 3 & \multirow[t]{3}{*}{0.107} \\
\hline & Transverse and posterior wall & 5 & 7 & \\
\hline & Bicolumnar fracture & 5 & 2 & \\
\hline \multirow[t]{2}{*}{ Dislocation } & posterior dislocation & 2 & 3 & \multirow[t]{2}{*}{1.000} \\
\hline & center hip dislocation & 4 & 4 & \\
\hline ASA grade & & $2.3 \pm 0.483$ & $\begin{array}{l}2.25 \pm \\
0.452\end{array}$ & 0.805 \\
\hline $\begin{array}{l}\text { Time from injury to } \\
\text { operation }(d)\end{array}$ & & $\begin{array}{l}20.70 \pm \\
1.176\end{array}$ & $\begin{array}{l}13.17 \pm \\
7.469\end{array}$ & 0.089 \\
\hline \multirow[t]{2}{*}{ Surgery approach } & Kocher-Langenbach approach & 4 & 8 & \multirow[t]{2}{*}{0.391} \\
\hline & $\begin{array}{l}\text { Combined anterior and } \\
\text { posterior approach }\end{array}$ & 6 & 4 & \\
\hline $\begin{array}{l}\text { Preoperative sciatic nerve } \\
\text { damage }\end{array}$ & & 0 & 0 & \\
\hline $\begin{array}{l}\text { Duration of the surgical } \\
\text { procedure }(m)\end{array}$ & & $\begin{array}{l}332.20 \pm \\
128.932\end{array}$ & $\begin{array}{l}257.50 \pm \\
91.589\end{array}$ & 0.128 \\
\hline $\begin{array}{l}\text { Blood loss during } \\
\text { operation (ml) }\end{array}$ & & $\begin{array}{l}1550.00 \pm \\
869.547\end{array}$ & $\begin{array}{l}666.67 \pm \\
370.094\end{array}$ & 0.011 \\
\hline Matta score & & $\begin{array}{l}1.1000 \pm \\
0.810\end{array}$ & $\begin{array}{l}2.4580 \pm \\
1.959\end{array}$ & 0.045 \\
\hline Harris hip score & & $\begin{array}{l}87.5000 \pm \\
10.522\end{array}$ & $\begin{array}{l}81.0000 \pm \\
10.126\end{array}$ & 0.078 \\
\hline Follow-up period & & $\begin{array}{l}29.2 \pm \\
4.6380\end{array}$ & $\begin{array}{l}25.9167 \pm \\
7.8098\end{array}$ & 0.257 \\
\hline
\end{tabular}


The duration of the surgical procedure was $332.20 \pm 128.932$ minutes in the NALP group and $257.50 \pm$ 91.589 minutes in the ALP group $(p=0.128)$. The intraoperative blood loss volume was $1550.00 \pm$ $869.5 \mathrm{ml}$ in the NALP group and $666.67 \pm 370.1 \mathrm{ml}$ in the ALP group. The ALP group had a significantly smaller mean intraoperative blood loss volume than the NALP group $(p=0.011)$. No patient had preoperative sciatic nerve damage.

\section{Radiographic outcome}

In the NALP group, the Matta scores indicated that the radiographic results were excellent in three patients (30\%), good in six (60\%), and fair in one (10\%). In the ALP group, the Matta scores indicated that the radiographic results were excellent in three patients (25\%), good in four (33.3\%), fair in two (16.7\%), and poor in three (25\%) (Table 2). The NALP group had significantly better radiographic results than the ALP group $(p=0.045)$ (Tables 1$)$.

Table 2

Radiographic grade according to the Matta score.

\begin{tabular}{|llllll|}
\hline Group & Excellent(<1 mm) & Good(1-2 mm) & Fair(2-3 mm) & Poor(>3 mm) & Total \\
\hline NALP & $3(30 \%)$ & $6(60 \%)$ & $1(10 \%)$ & 0 & 10 \\
$(\mathrm{n}(\%))$ & & & & & \\
\hline ALP & $3(25 \%)$ & $4(33.3 \%)$ & $2(16.7 \%)$ & $3(25 \%)$ & 12 \\
$(n(\%))$ & & & & & \\
\hline
\end{tabular}

\section{Functional outcome}

The hip functional results are summarized in Tables 1 and 3. In the NALP group, the Harris hip score indicated that the hip function was excellent in four patients (40\%), good in five $(50 \%)$, fair in $0(0 \%)$, and poor in one (10\%). In the ALP group, the Harris hip score indicated that the hip function was excellent in four patients (33.3\%), good in four (33.3\%), fair in three (25\%), and poor in one (8.3\%). Although the postoperative hip function was not significantly different between the groups $(t=1.473, p=0.078)$, the $p$ value was small, indicating a possible difference between them.

Table 3

Clinical outcomes according to the Harris hip score.

\begin{tabular}{|llllll|}
\hline Group & Excellent $(\geq 90)$ & Good(80-89) & Fair(70-79) & Poor(\$70) & Total \\
\hline NALP $(n(\%))$ & $4(40 \%)$ & $5(50)$ & $0(0)$ & $1(10 \%)$ & 10 \\
\hline ALP $(n(\%))$ & $4(33.3 \%)$ & $4(33.3 \%)$ & $3(25 \%)$ & $1(8.3 \%)$ & 12 \\
\hline
\end{tabular}

One patient in each group developed femoral head necrosis in about 2 years. The patient in the NALP group had a transverse and posterior acetabular wall fracture with posterior dislocation, and the time 
from injury to the operation was 6 weeks. The patient in the ALP group had a double-column acetabular fracture with posterior dislocation, and the time from injury to the operation was 10 days.

\section{Discussion}

The incidence of acetabular fractures has increased in China during the last 20 years [18]. The primary goals of acetabular fracture surgery are anatomical reduction and strong fixation [7], which ensure early postoperative mobilization and reduce the incidence of traumatic arthritis or hip ankyloses. The ALP facilitates strong fracture fixation and early mobilization. However, because of the fixation of the locking screw, use of the ALP incurs a risk of the screw entering the acetabulum, as with other non-locking plates. Furthermore, the shape of the ALP and the angle of the screw may limit the compression of the fracture ends, leaving a residual gap [19].

The NALP consists of an inverted Y-shaped structure that matches the inverted Y-shaped structure of the acetabulum [20] (Fig. 3). The NALP is anatomically contoured to match the surface of the posterior column of the acetabulum of Chinese patients; therefore, this plate can be used directly without the need for manual precontouring, which reduces the surgical time [11]. The NALP has a fan-shaped wing guard in the region of the acetabular top with the largest load; this wing guard structure and locking screw helps obtain more stable fixation in patients with a fixed femolar top comminuted. The guide holes in the NALP were designed to guarantee the appropriate starting points for the anterior column screws and the Magic screws, respectively, making it easier to safely place minimally invasive screws. These two screws pressurize the fracture line of the anterior column, while the posterior column is pressurized via the single Kocher-Langenbeck approach.

In the present study, the ALP group tended to have a shorter operation time than the NALP group, but this difference was not significant. The NALP group had a significantly larger mean intraoperative blood loss volume than the ALP group. For many patients in the NALP group, the time from injury to the operation was longer than 3 weeks; i.e., many patients in the NALP group had older fractures. Bicolumnar fractures were also more common in the NALP group. These fractures were more difficult to treat, which delayed the surgery.

The NALP group had significantly higher fracture gaps than the ALP group. The rates of excellent and good radiographic results based on the Matta scores in the NALP and ALP groups were $90 \%$ and $58.3 \%$, respectively. In the NALP group, the Matta scores indicated that $10 \%$ of patients achieved fair results and that no patients achieved poor results. In the ALP group, the Matta scores indicated that $16.7 \%$ of patients achieved fair results and $25 \%$ achieved poor results. The NALP group achieved superior radiographic results because the compression screw enables the NALP to pressurize the fracture ends, reduce the gap at the fracture ends, and improve the reduction outcome.

The rates of excellent and good functional results based on the Harris hip scores in the NALP and ALP groups were $90.0 \%$ and $66.6 \%$, respectively. Each group contained one patient with a poor result due to osteonecrosis of the femoral head; both patients had posterior dislocation. The Harris hip scores 
indicated that three patients in the ALP group achieved fair results. The Harris hip scores indicated that the hip function tended to be superior in the NALP group than in the ALP group, but this difference was not significant. Although the reduction of the acetabular fracture strongly influences the functional score of the hip, the Harris hip score is also affected by many other factors.

When the ALP was used for fixation, acetabular anatomical reduction was required, and the fracture ends could not be compressed after plate fixation. When using the NALP, the compression screws were driven into the anterior and posterior columns through the plate to compress the acetabular fracture ends. However, although the auxiliary insertion point was provided when the NALP was used, the correct implantation was also dependent on the combined application of the guide module and the perspective, which increased the operation time [21, 22].

In our experience, several important aspects must be considered when using the NALP for acetabular fractures. (1) Because the structure of the NALP is designed based on the posterior acetabular morphology of Chinese patients, the Kocher-Langenbeck approach or the combined anterior and posterior approach must be used. (2) Neither the NALP nor ALP must necessarily totally fit the contour of the patients. The locking feature provides adequately stable fixation for rehabilitation. (3) After the NALP is placed, the best compression is achieved by inserting the anterior column screws and Magic screws before inserting the other locking screws.

The present study had some limitations, including the retrospective study design and relatively small sample size. The present findings require confirmation in prospective randomized controlled trials with large sample sizes.

\section{Conclusion}

The present findings suggest that the NALP achieves strong compression of the ends of an acetabular fracture and obtains better reduction and function status than the ALP. The NALP may be the best choice for the treatment of acetabular fractures rather than other reconstructed plates in Chinese patients.

\section{Abbreviations}

NALP: novel anatomical locking plate

ALP: anatomical locking plate

\section{Declarations}

\section{Ethics approval and consent to participate:}

This study was approved by the ethics committee of the Chinese PLA General Hospital. 


\section{Consent for publication:}

Not applicable.

\section{Availability of data and material:}

Not applicable.

\section{Competing interests:}

The authors declare that they have no competing interests.

\section{Funding:}

This study was supported by the National Key R\&D Program of China (2017YFB1304200), National Natural Science Foundation of China (61771489), and Capital Characteristic Clinic Project (z171100001017198).

\section{Authors' contributions:}

ZG and ZS participated in the data collection and drafted the manuscript. SY and WX participated in the design of the study and performed the statistical analysis. SX and CZ performed the statistical analysis. TP and ZL conceived of the study and participated in its design and coordination and helped to draft the manuscript. All authors read and approved the final manuscript.

\section{Acknowledgments}

We thank Liwen Bianji, Edanz Editing China (www.liwenbianji.cn/ac), for editing the English text of a draft of this manuscript.

\section{References}

1. Guerado, E., J.R. Cano, and E. Cruz, Fractures of the acetabulum in elderly patients: an update. Injury, 2012. 43 Suppl 2: p. S33-41.

2. Baschera, D., et al., Incidence and clinical relevance of heterotopic ossification after internal fixation of acetabular fractures: retrospective cohort and case control study. J Orthop Surg Res, 2015. 10: p. 60 . 
3. Giannoudis, P.V., et al., Operative treatment of displaced fractures of the acetabulum. A metaanalysis. J Bone Joint Surg Br, 2005. 87(1): p. 2-9.

4. Matta, J.M., Fractures of the acetabulum: accuracy of reduction and clinical results in patients managed operatively within three weeks after the injury. J Bone Joint Surg Am, 1996. 78(11): p. 1632-45.

5. Gary, J.L., et al., Functional outcomes in elderly patients with acetabular fractures treated with minimally invasive reduction and percutaneous fixation. J Orthop Trauma, 2012. 26(5): p. 278-83.

6. Borg, T. and N.P. Hailer, Outcome 5 years after surgical treatment of acetabular fractures: a prospective clinical and radiographic follow-up of 101 patients. Arch Orthop Trauma Surg, 2015. 135(2): p. 227-233.

7. Ferguson, T.A., et al., Fractures of the acetabulum in patients aged 60 years and older: an epidemiological and radiological study. J Bone Joint Surg Br, 2010. 92(2): p. 250-7.

8. Peng, Y., et al., Comparison of anterograde versus retrograde percutaneous screw fixation of anterior column acetabular fractures. Int J Comput Assist Radiol Surg, 2016. 11(4): p. 635-9.

9. Mears, D.C., J.H. Velyvis, and C.P. Chang, Displaced acetabular fractures managed operatively: indicators of outcome. Clin Orthop Relat Res, 2003(407): p. 173-86.

10. Xu, M., et al., Development of site-specific locking plates for acetabular fractures. Orthopedics, 2013. 36(5): p. e593-600.

11. Xu, M., et al., Custom-made locked plating for acetabular fracture: a pilot study in 24 consecutive cases. Orthopedics, 2014. 37(7): p. e660-70.

12. Zhang, L., et al., Percutaneous Anterior Column Fixation for Acetabulum Fractures, Does It Have to Be Difficult?-The New Axial Pedicle View of the Anterior Column for Percutaneous Fixation. Journal of orthopaedic trauma, 2016. 30(1): p. e30-5.

13. Zhang, L., et al., Experimental study on treatment of acetabular anterior column fractures: applyment of a minimally invasive percutaneous lag screw guide apparatus. Bmc Musculoskeletal Disorders, 2016. 17(1): p. 1-7.

14. Lin, F.J., et al., Evaluating change using patient-reported outcome measures in knee replacement: the complementary nature of the EQ-5D index and VAS scores. Eur J Health Econ, 2014. 15(5): p. 489-96.

15. Spens, H. and G.C. Pugh, Measurement of VAS pain scores with a 'magic screen'. Anaesthesia, 1992. 47(4): p. 359-60.

16. Edmunds, C.T. and P.J. Boscainos, Effect of surgical approach for total hip replacement on hip function using Harris Hip scores and Trendelenburg's test. A retrospective analysis. Surgeon, 2011. 9(3): p. 124-9.

17. Ai, Z., et al., [Analysis on Harris scores at follow-up after internal fixation of femoral neck fracture]. Zhongguo Xiu Fu Chong Jian Wai Ke Za Zhi, 2009. 23(4): p. 435-9.

18. Mauffrey, C., et al., The epidemiology and injury patterns of acetabular fractures: are the USA and China comparable? Clin Orthop Relat Res, 2014. 472(11): p. 3332-7. 
19. Mehin, R., et al., A biomechanical study of conventional acetabular internal fracture fixation versus locking plate fixation. Can J Surg, 2009. 52(3): p. 221-8.

20. Judet, R., J. Judet, and E. Letournel, Fractures of the Acetabulum: Classification and Surgical Approaches for Open Reduction. Preliminary Report. J Bone Joint Surg Am, 1964. 46: p. 1615-46.

21. Peng, Y., et al., Comparison of anterograde versus retrograde percutaneous screw fixation of anterior column acetabular fractures. International Journal of Computer Assisted Radiology and Surgery, 2016. 11(4): p. 635-639.

22. Li, J., et al., Establishment of fluoroscopy views and standardized procedure of percutaneous magic screw insertion for acetabulum fractures. BMC Musculoskelet Disord, 2018. 19(1): p. 332.

\section{Figures}



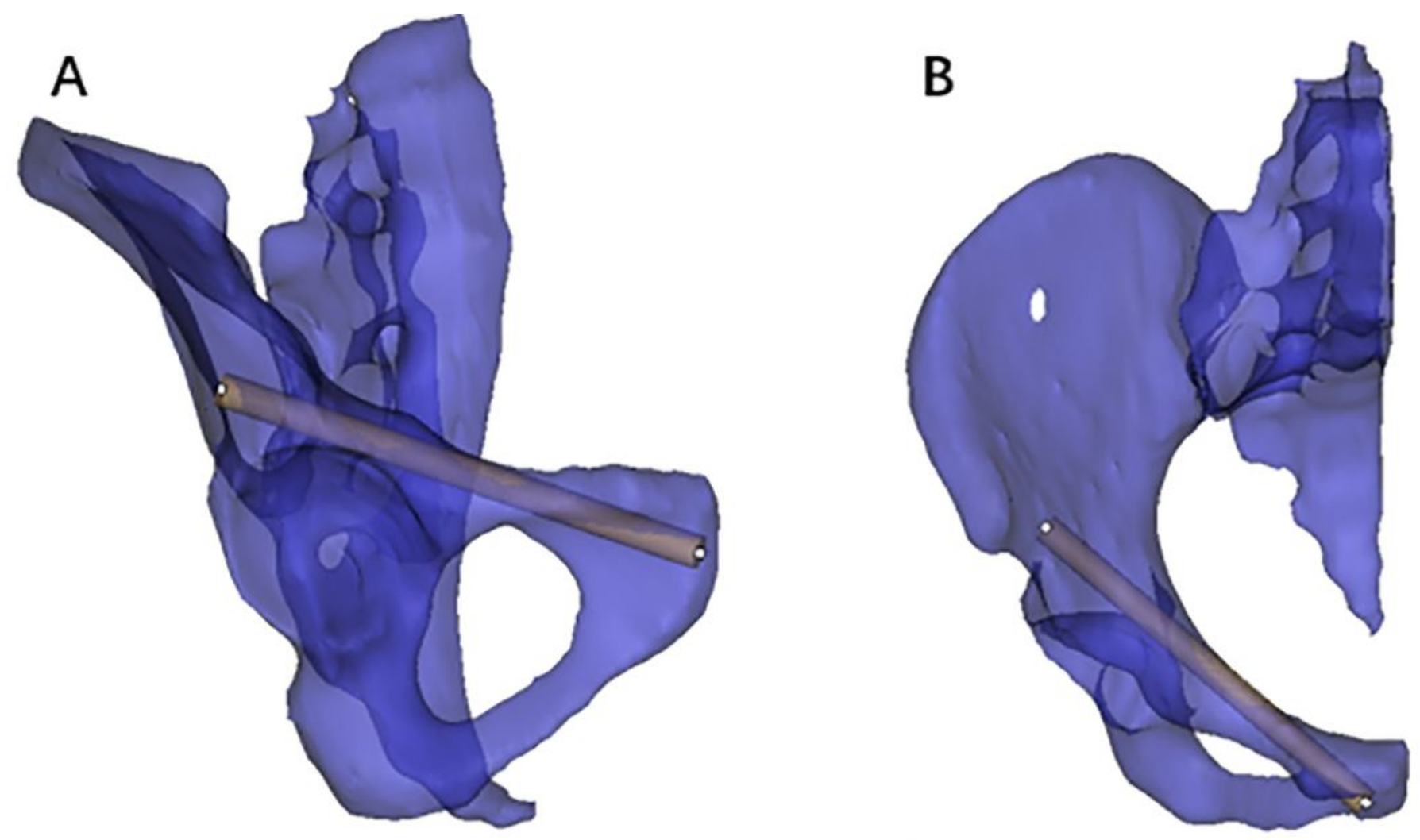

C
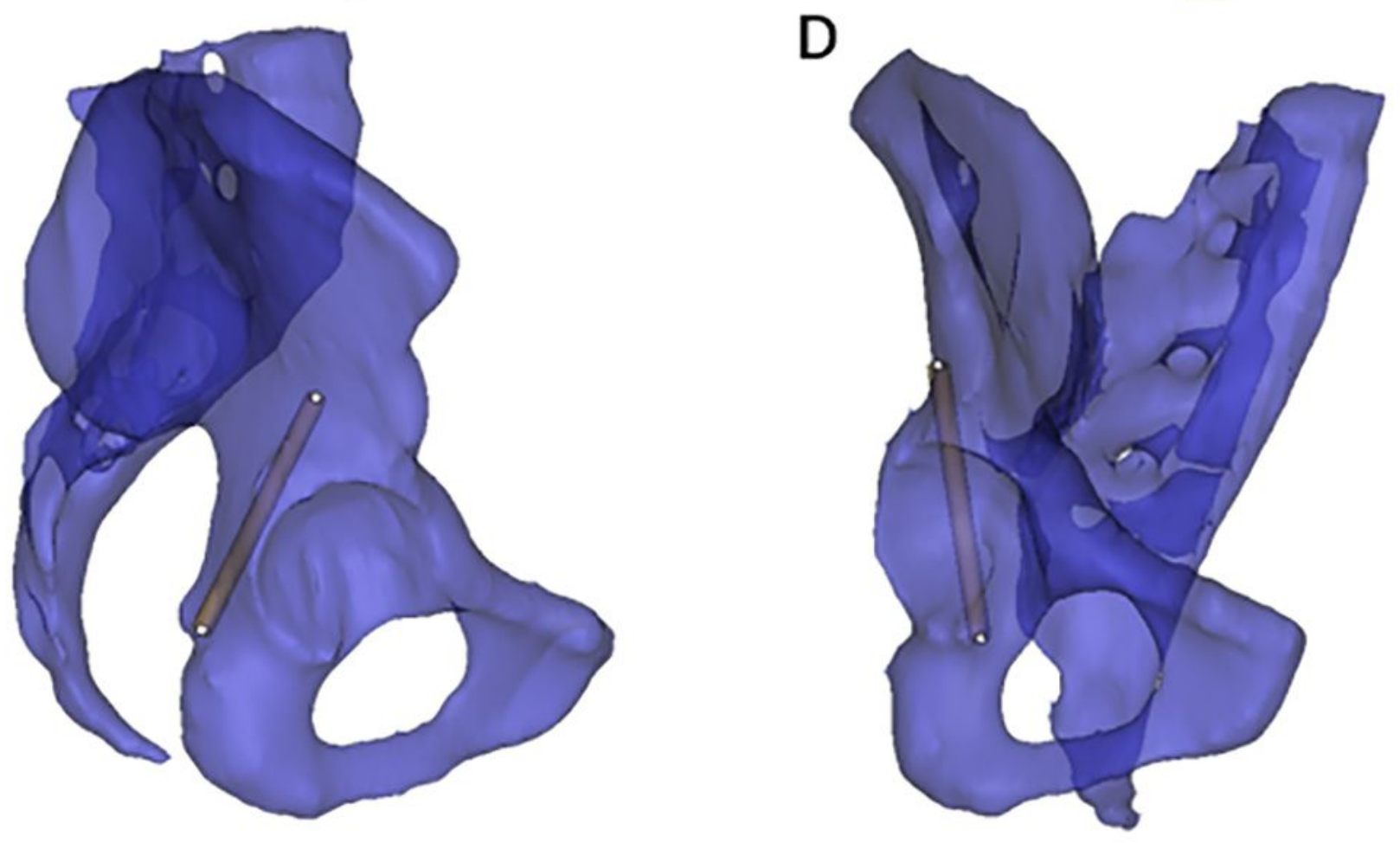

\section{Figure 1}

$A, B$ : The channel morphology of the anterior column and the placement position of the front column screw. C, D: The channel shape of the Magic screw for posterior column fixation and the placement position of the Magic screw. 

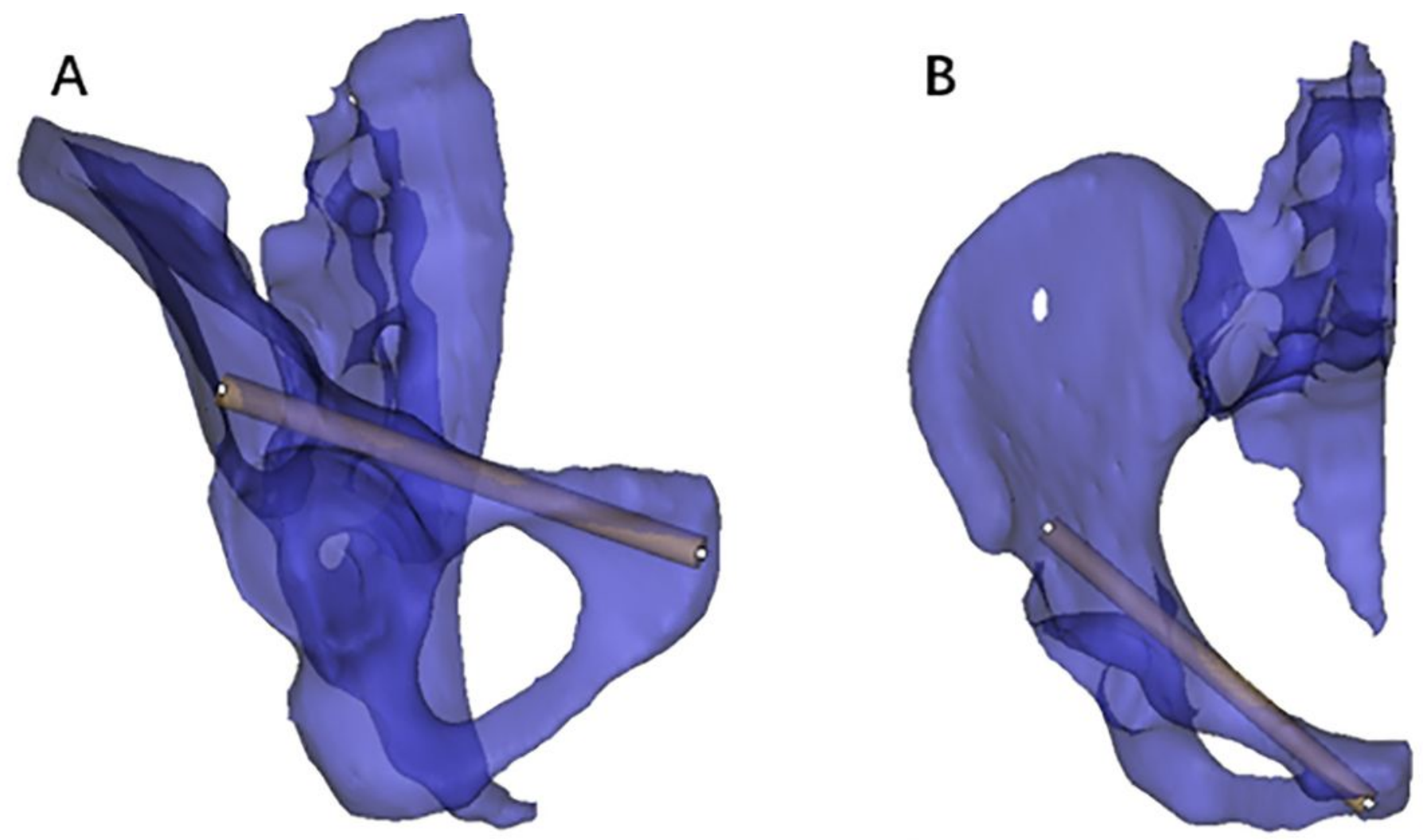

C
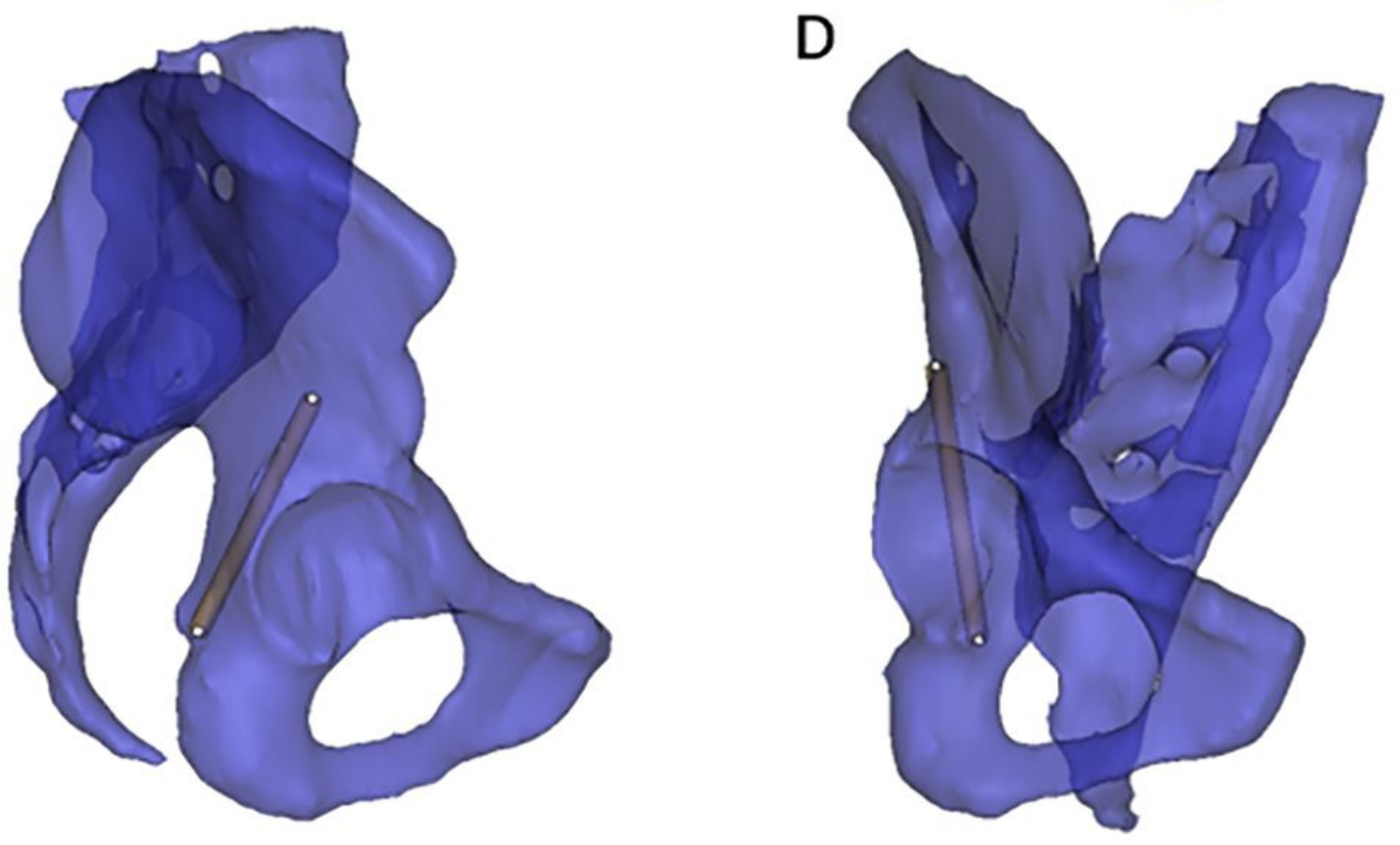

\section{Figure 1}

$A, B$ : The channel morphology of the anterior column and the placement position of the front column screw. C, D: The channel shape of the Magic screw for posterior column fixation and the placement position of the Magic screw. 

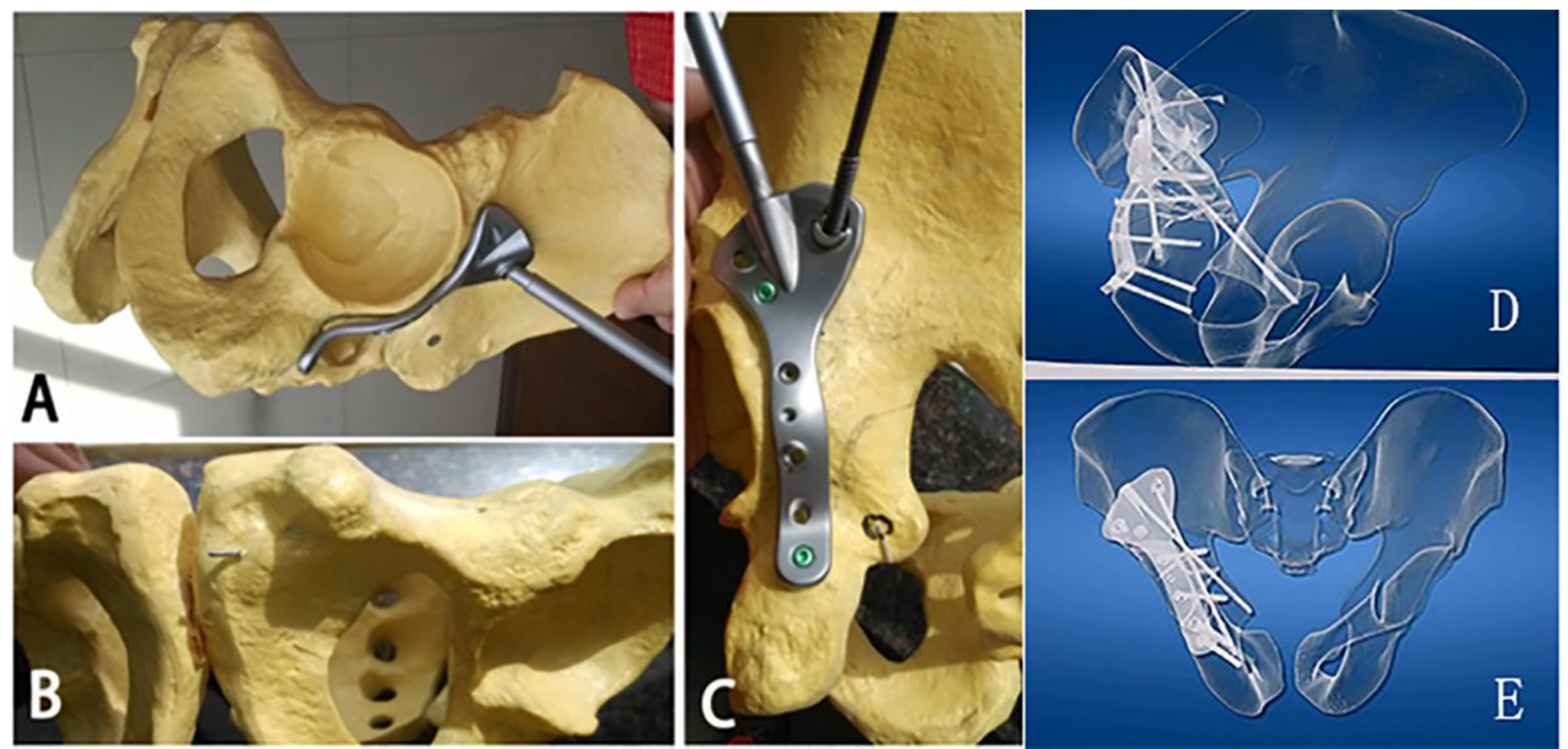

Figure 2

A-C: Anatomical locking plate placement and screw position with anterior column screws and Magic screws. D, E: The screw forms a " $\mathrm{Y}$ " structure with the steel plate in the anterior and posterior column, achieving simultaneous compression.
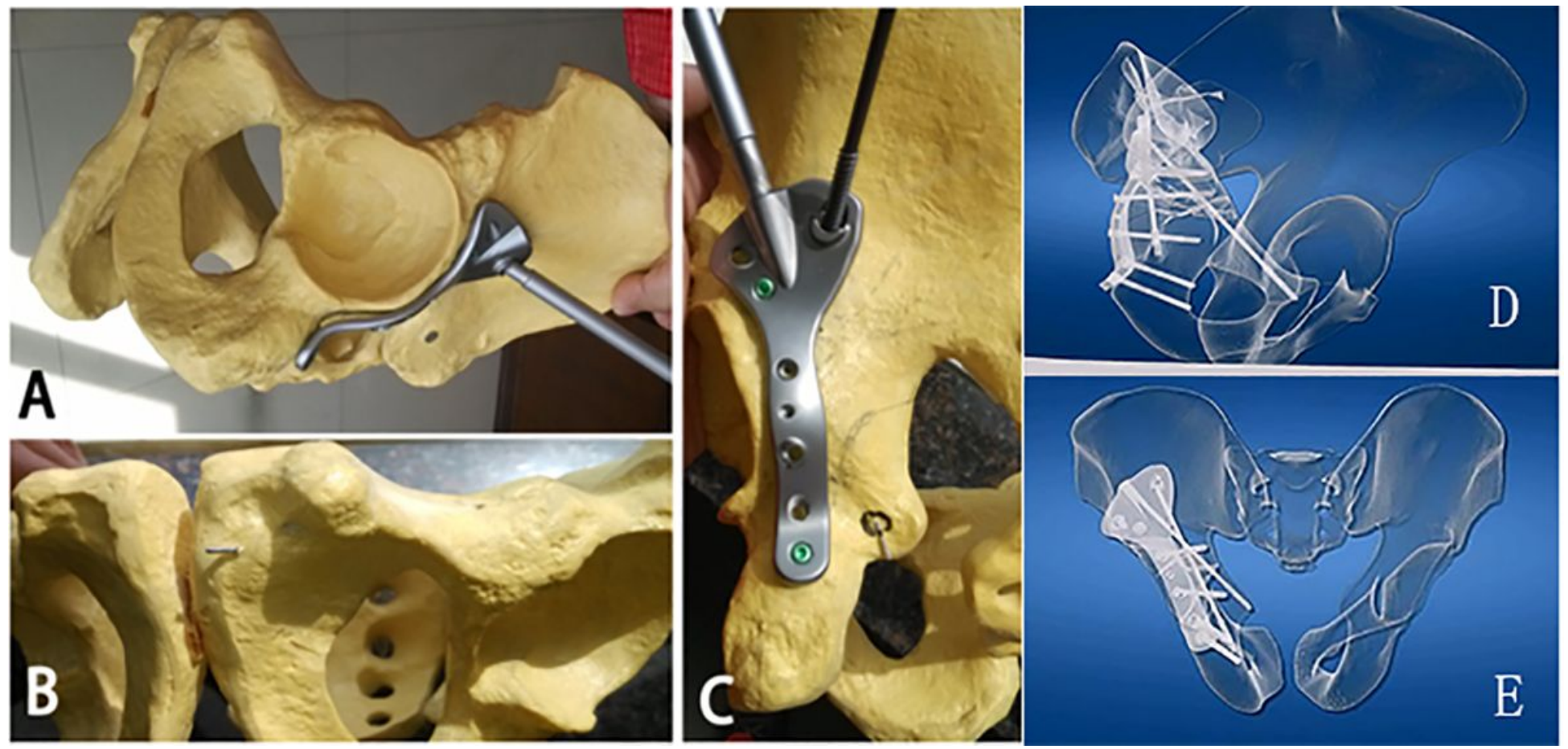

Figure 2

A-C: Anatomical locking plate placement and screw position with anterior column screws and Magic screws. D, E: The screw forms a "Y" structure with the steel plate in the anterior and posterior column, 


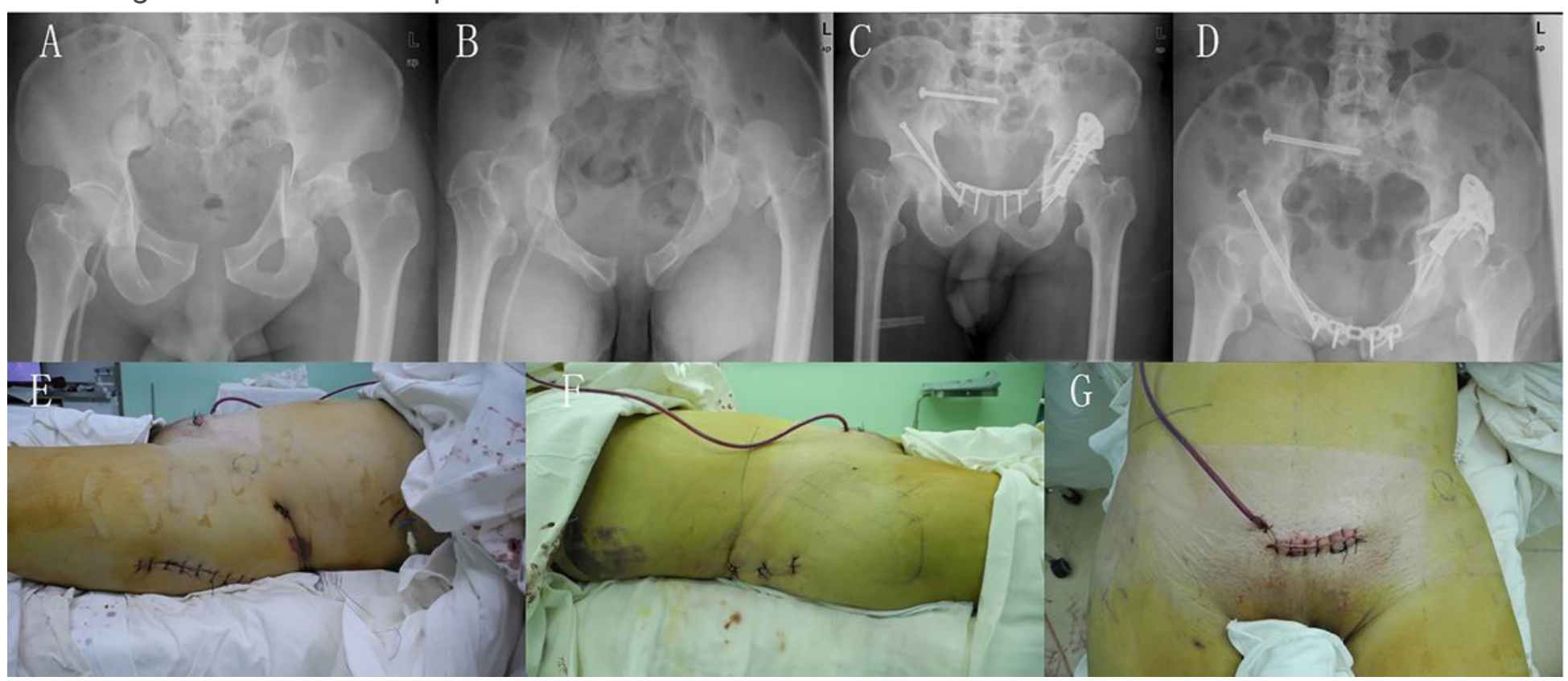

\section{Figure 3}

One patient with pelvic acetabular fractures. A, B: Preoperative fracture condition. C, D: Postoperative fracture condition. E-G: Skin incision through a simple posterior approach to achieve simultaneous anterior and posterior column pressure fixation.

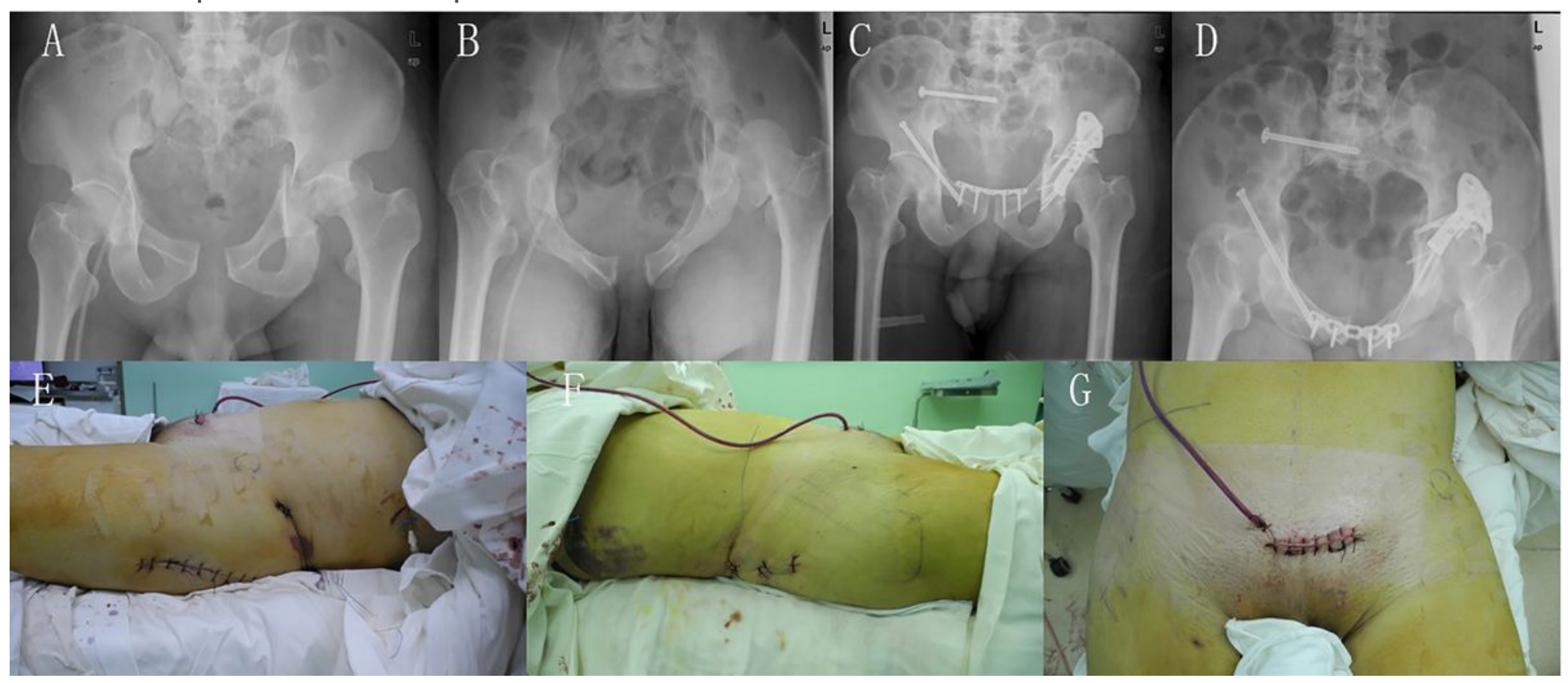

\section{Figure 3}

One patient with pelvic acetabular fractures. A, B: Preoperative fracture condition. C, D: Postoperative fracture condition. E-G: Skin incision through a simple posterior approach to achieve simultaneous anterior and posterior column pressure fixation. 